\title{
RIVER BED LEVEL VARIATION IN KINU RIVER AND ITS EFFECT ON SAFETY MARGIN
}

\author{
Nobuyuki TAMAI*, Mohammad Mafizur RAHMAN**, Hironori MATSUZAKI***
}

\begin{abstract}
The river bed variation is a natural process. In the master plan, though the river bed and the water surface stage is shown to have a smooth profile and the safety measures are taken accordingly but in reality the case is not exactly so. The natural variation of the bed level from such smoothness in the longitudinal direction in a $13 \mathrm{~km}$ reach of Kinu river was analyzed. Through the 1-D steady flow simulation the associated variation in the water surface stage was analyzed. The subsequent probability of water surface to overtop the design levee height is near $1 \%$. Such consequences should also be taken into account in the reliability analysis of flooding.
\end{abstract}

Key words: Bed level variation, water surface stage, Uncertainty, 1-D model

\section{Introduction:}

The river master plan considers the longitudinal river bed profile to have a smooth profile. Such master plan also shows water surface stage to have a smooth longitudinal profile. Based on such planning assumptions the levee height is designed. The designed levee maintains the same freeboard along the longitudinal reach. But in reality, the river bed is under the process of natural variation and it hardly follows such smooth profile. The present study analyses the behavior of such variation with its subsequent effect on the safety considerations of the flood control planning.

The investigation area covers a river reach of 13.0 kilometers of the Kinu river. The downstream and upstream sections of the investigation reach are respectively $45.0 \mathrm{~km}$. and 58.0 $\mathrm{km}$. upstream of the Tone river confluence. (Note: hereafter, section 45 will refer to the most downstream section of the reach and 58 will refer to the most upstream reach and so will be true for the rest of the sections also).That means the reach is selected such that there is no branching of the river within this portion. Another aspect to be observed regarding the location of the experimental reach is that in the upstream side- beyond the reach, the bed slope is very steep (ranging between 0.002 to 0.005 ) and that in the downstream direction beyond the reach is flatter(ranging between 0.0004 to 0.0006 ). That means this portion of Kinu river is in a zone of transitional slope.

\section{Stream Geometry Data:}

For Kinu river only the annual river cross sectional geometry data is available. The crosssectional river geometry map of the Kinu river for the years 1977,1981,1983 and 1989 were obtained. The pitch was $0.5 \mathrm{~km}$. and hence there were 27 river cross- sectional geometry data sets for each of the four years. The number of digitized data points per cross-section ranges from 54 to 201 with an average of 110 . The bed actual slope within the reach varies between $1 \mathrm{~m}$ to $2 \mathrm{~m}$ per $\mathrm{km}$. A typical section as shown in Fig. 1 is for the section 45 surveyed in 1989.

\footnotetext{
* Fellow Professor, Department of Civil Engineering, University of Tokyo

** Graduate School, Department of Civil Engg., University of Tokyo

**** Member Research Associate, Department of Civil Engg., Univ. of Tokyo
} 


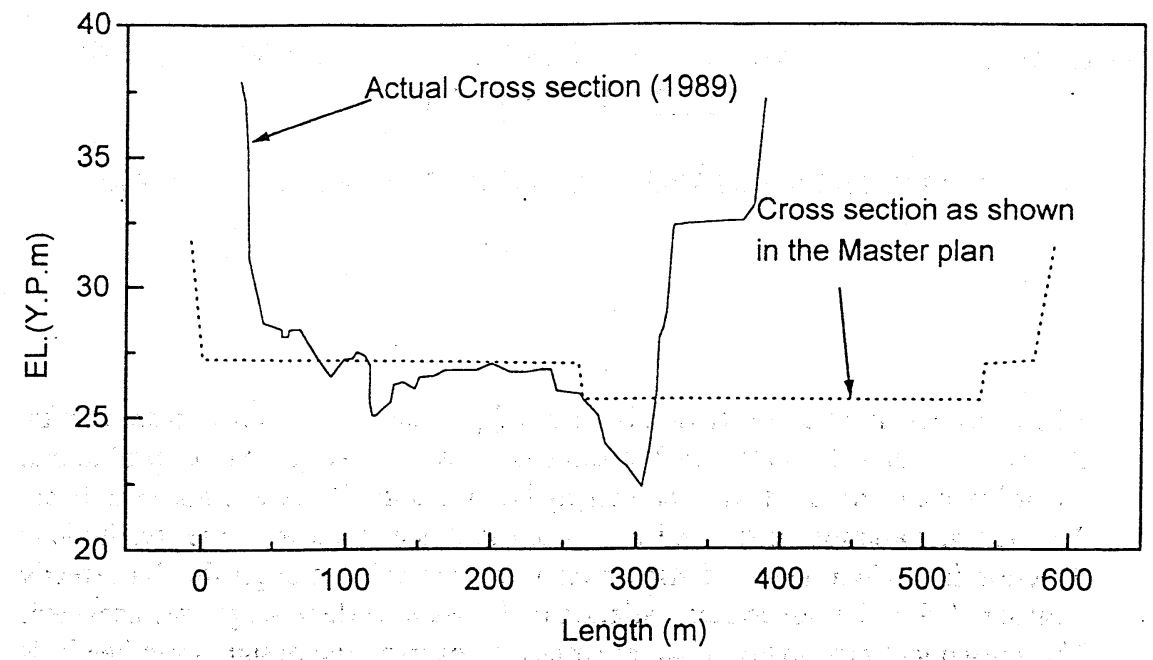

Fig.1 The actual and real cross sectional profile for section 45

\section{Mathematical Model:}

Water surface profile for the reach for each year was computed by a 1-D model (Samuel,1995) (Fong,1989)using the standard step (step-profile) method for steady-flow (Burnham,1990) condition. The method solves the steady-flow equations by applying a cross section-to-cross section, step-by-step procedure (Chaudhry,1993)(Chow,1959).Along with the continuity equation the energy equation solved in the 1-D model was:

$$
F\left(y_{2}\right)=y_{2}+\frac{Q^{2}}{2 g A_{2}^{2}}+\frac{1}{2} S_{f_{2}}\left(x_{2}-x_{1}\right)+z_{2}-H_{1}+\frac{1}{2} S_{f_{1}}\left(x_{2}-x_{1}\right)=0
$$

where the initial approximation of the consecutive upstream section water depth was done by

$$
\frac{d y}{d x}=\frac{S_{0}-S_{f}}{1-\frac{Q^{2} B}{g A^{3}}}
$$

where the suffices 1 and 2 refer to the present section (downstream) and the next section (upstream) respectively in the iteration. In equations (1) and (2) the notations used are as follows $S_{f}=$ the slope of energy grade line at any section, $S_{0}=$ the longitudinal bed slope, $\mathrm{H}=$ the total head at any section, $y=$ depth of flow, $x=$ the longitudinal distance of the river reach ( positive in the downstream direction), $\mathrm{z}=$ elevation of the channel bottom above a specified datum, $\mathrm{A}=$ cross sectional area of the river.

Energy coefficients in all cases were assumed to be 1.0. Newton- Raphson's method was followed for the iteration.

As input data -the bed slope, Manning's roughness coefficient (n), water depth at the downstream section and flow rate $(\mathrm{Q})$ were given. The Manning's roughness coefficient (n) was assumed to be constant $(=.035)$ for all the simulation cases. This value of $n$ was suggested in the master plan of Kinu river. The actual bed slope data was also obtained.

As input data, the depth of flow at the downstream section and the discharge( $Q$ ) were given. The water depth (with respect to bed) at the downstream section and the respective flow rate $(Q)$ used as input data for any specific year were generated by an individual program. As the lower boundary condition Manning's uniform flow equation was used for a range of flow depths to generate the respective discharge $(\mathrm{Q})$ value. For example, for the year 1989 the actual digitized cross-section(of section 45) was used and for a range of depth of flow- the Manning's equation gave the respective discharge value. Later, from the selection of the desired value of $Q$ the respective depth of flow for section 45 was selected. 
As input data; the number of total digitized data for the respective section alongwith the number of initial and the final points where the calculation should start and terminate. These two are actually the highest points on each side of the thalweg within which the water is bounded.

The program calculates the geometrical parameters such as the area of the cross section, wetted perimeter (the hydraulic radius), the top width of a natural river cross section of any arbitrary shape. As output it gives the depth of flow, the longitudinal variation of water surface stage which in other words is produced from its ability to calculate the longitudinal thalweg profile.

\section{Mathematical Experimentation/ Calculations:}

The design depth of flow as shown in the master plan is $8.6 \mathrm{~m}$ at section 45 . The respective design discharge is $5300 \mathrm{~m}^{3} / \mathrm{s}$. For this value of discharge and the corresponding depth of flow of section 45 for the digitized section in each of the four years were used in the simulation. These gave the water surface profile for the design discharge in each of the four years corresponding to the actual cross sectional shape and hence the actual longitudinal profile.

Fig. 3 shows the natural rugged behavior of the longitudinal bed profile for four years $(1977,1981,1983$ and 1989) compared to the smooth bed profile shown by the master plan. The water surface stage profile for the year 1989 is also shown in Fig. 2 with the corresponding longitudinal bed profile.

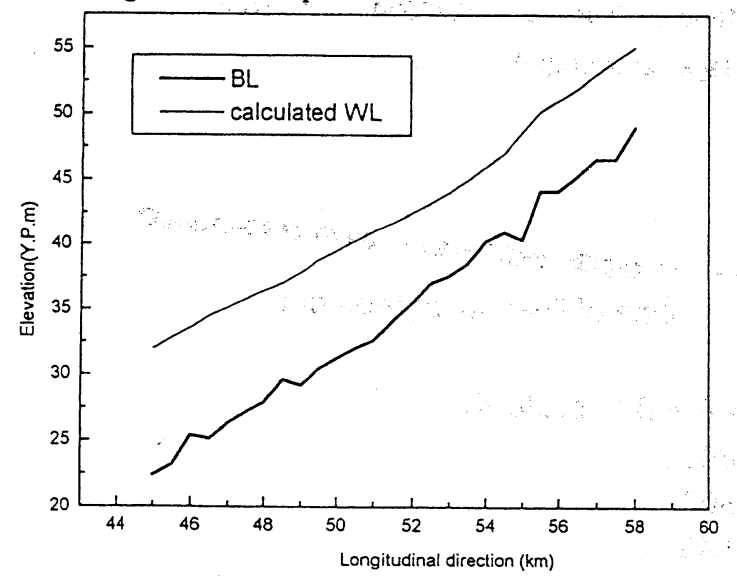

Fig.2The calculated longitudinal profile of water surface and the bed of Kinu tiver in 1989

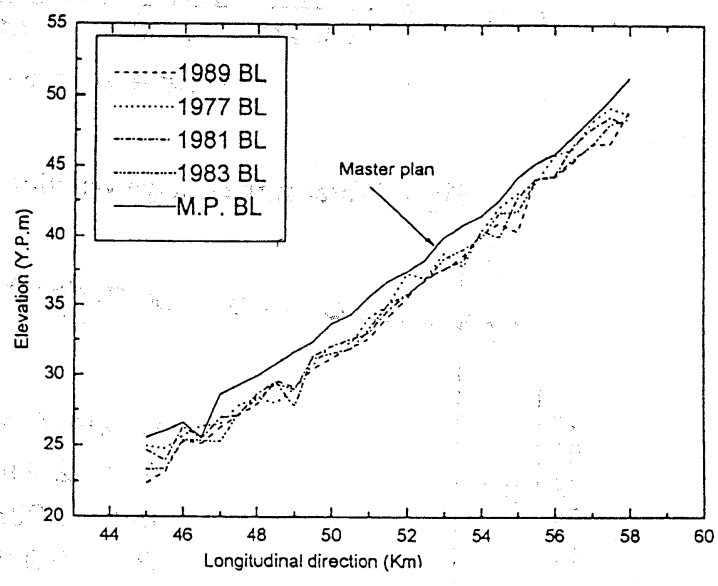

Fig. 3 Longitudinal thalweg profile of the studied $13.0 \mathrm{~km}$ reach of Kinu river as per Master plan and in $1977,1981,1983$ and 1989

\section{Analysis:}

The longitudinal water surface stage profile and the longitudinal bed profile was made smooth by the moving average method. In this case, the three point moving average was selected. Then the deviation of the longitudinal water surface stage profile was determined from that of the moving averaged smooth profile at each of the longitudinal locations where the cross sectional data was obtained. In the similar way the deviation at the same locations. were determined for the river bed, also for all the four years.

\section{Discussion and Results:}

The longitudinal water surface stage profile and the longitudinal bed profile were smoothed because the purpose of the study was to analyze their natural variation with respect to that of the smoothed one like in the master plan. 
The distribution of the deviations of the longitudinal profile of both bed and water stage follows the log-normal distribution. The linearity of relationship of the variates and their cumulative frequencies when plotted in the log-normal probability paper is shown in Fig. 4 and Fig.5 for both the cases. The linear best fit line is drawn in the figures and the corresponding parameters found by the least square method are also enlisted. The maximum, mean and the standard deviation of the deviations are shown in Table 1. Respective log-normal parameters $(\lambda$ and $\zeta)$ and the chisquared $\left(\chi^{2}\right)$ values of goodness of fit test are also given. As goodness of fit , Chi-square test(Aan and Tang) was done for the confidence level of $95 \%(=1-\alpha)$ and the degree of freedom $(=f)$ of 105 for both the cases. The respective percentile values (Aan and Tang) of the Chi-square distribution are also given in Table1.

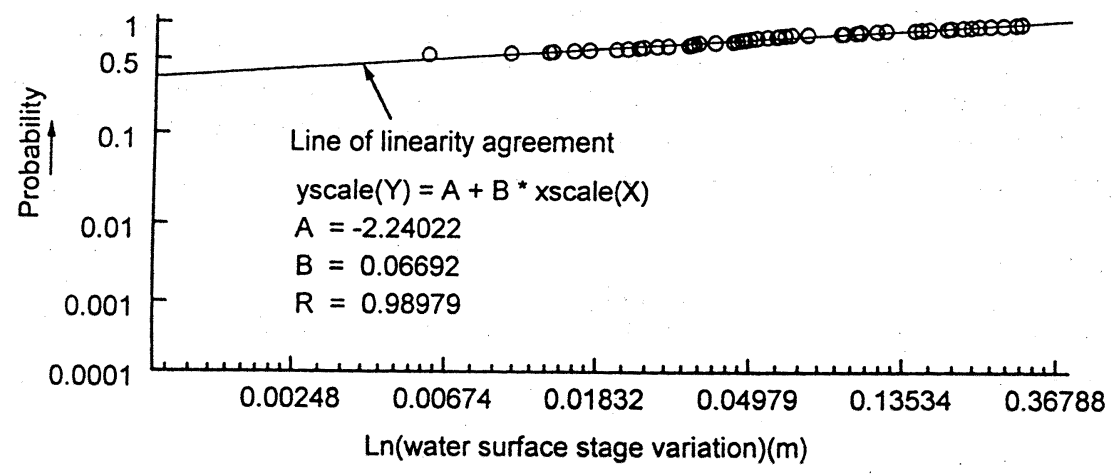

Fig 4. Water surface stage variation

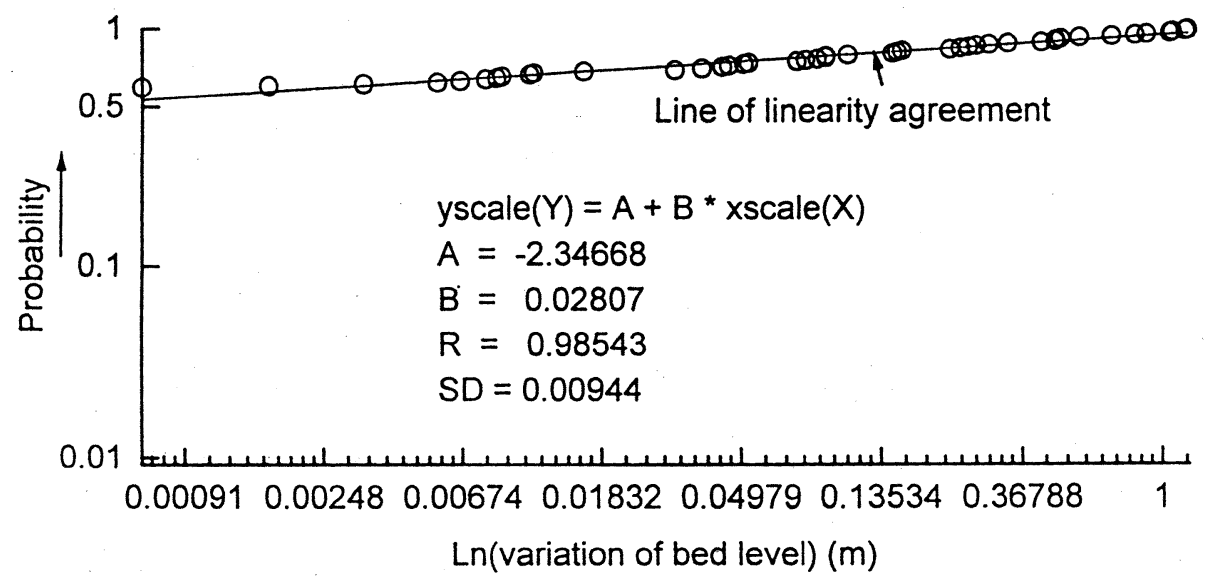

Fig. 5 The bed level variation

Table 1. Statistics of the variations of bed and water surface stage

\begin{tabular}{l|ccccccc}
\hline Deviation for the profile of & $\begin{array}{c}\text { Mean } \\
(\mathrm{m})\end{array}$ & $\begin{array}{c}\text { Std. Dev. } \\
(\mathrm{m})\end{array}$ & $\begin{array}{c}\text { Max. } \\
(\mathrm{m})\end{array}$ & $\lambda$ & $\zeta$ & $\chi^{2}$ & $C_{\text {l-aff }}$ \\
\hline Water surface stage & 0.09 & 0.08 & 0.29 & -2.67 & 0.7619 & 0.27 & 77.9 \\
Bed elevation & 0.28 & 0.36 & 1.0 & -1.748 & 0.9242 & 7.75 & 77.9 \\
\hline
\end{tabular}

For the reach of Kinu river the probability of the exceedence of deviation of the water surface stage above its smooth profile by $1.5 \mathrm{~m}$ (the freeboard height) is $1 \%$. 
As shown in Table 1, the mean of the deviation of the water surface stage about the moving average was $0.09 \mathrm{~m}$. The $95 \%$ confidence upper and lower bounds were 0.1 and $0.01 \mathrm{~m}$ respectively as are shown by the qualitative diagram in Fig.6. In the figure the mean of the water stage deviation only in the upper part of the moving averaged line is shown. As the objective of the study is to highlight the probability of exceedence of water surface over the levee so the line below the moving averaged water stage surface was excluded in Fig. 6.

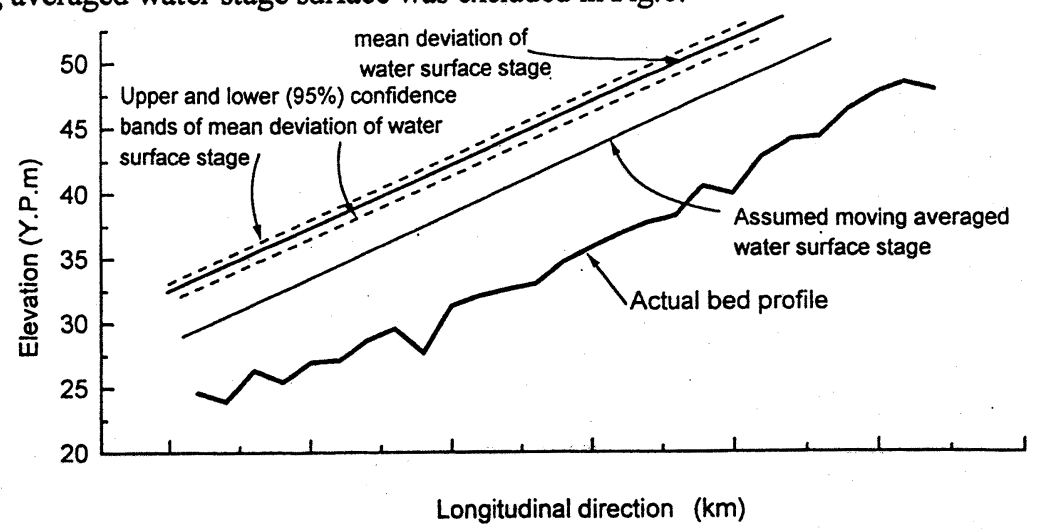

Fig.6 The average of variation of the water surface stage profile about the moving average is shown with the $95 \%$ confidence bands in a qualitative diagram (For convenience the vertical scale has been exaggerated)

\section{Conclusion:}

The present study considers the characteristics of natural variation of the river bed which is an obvious natural phenomenon. The corresponding variation characteristics of the water surface stage was also analyzed. Both of these were found to follow the log-normal distribution. The return period of the exceedence of the water stage above the levee height is almost 100 years. This sort of risk retained from the natural uncertainty of the bed is important and should be taken into consideration by the river planners. This scope, in another way is a source of uncertainty. For an existing river, such consequences should be taken into consideration for the detailed study of the reliability analysis.

\section{Acknowledgment:}

The authors wish to express thanks to the Shimodate branch office of Ministry of Construction of Japan- for their co-operation to provide the Kinu river cross sectional geometry annual survey maps of four years for the studied area and the master plan.

\section{References:}

1) ANG A.H.S. and TANG W.H. : Probability Concepts in Engineering Planning and Design, Vol $1,409 \mathrm{p}$, John Wiley and Sons, (1975).

2) ANG A.H.S. and TANG W.H. : Probability Concepts in Engineering Planning and Design, Vol 2, 562p, John Wiley and Sons, (1984)

3) BURNHAM M.W. and DAVIS D.W:: Effects of Data Errors on Computed Steady Flow Profiles, Journal of Hydraulic Engineering, ASCE, Vol. 116, No.7, 914-929,(1990).

4) CHAUDHRY M. HANIF: Open Channel Flow,483p, Prentice Hall,Inc.(1993)

5) CHOW, V. T. : Open Channel Hydraulics, 680p, McGraw-Hill Book Company (1959).

6) FONG S. I.: Risk Analysis on Flood Levee Design, Dissertation Paper of M.Engg., Department of Civil Engg., University of Tokyo, 108p,(1989).

7) SAMUEL P.G.: Uncertainty in Flood Levee Prediction, Hydra 2000(Vol. 1),567-572,Thomas Telford, London(1995). 